\title{
The Development of Online Training Curriculum base on Micro Learning and Online Social Network for Teacher in 21st Century in Test Construction Topic
}

\author{
Ruangdech Sirikit $^{1}$, Panwasn Mahalawalert ${ }^{2}$, Areeya Sriprasert ${ }^{3}$ \\ ${ }^{1,2}$ Educational and Psychological Test Bureau, Srinakharinwirot University, Bangkok, Thailand \\ ${ }^{3}$ School of Information Technology, Eastern Asia University, Bangkok, Thailand
}

\begin{abstract}
The objectives of this research were 1) to develop the online training curriculum based on Micro Learning and Online Social Network for 21st century teachers on test creation, and 2) to evaluate the effectiveness of the online training curriculum based on Micro Learning and Online Social Network for 21 st century teachers on test creation. The methodology was divided into 2 steps:Step 1 was the development of the online training curriculum based on Micro Learning and Online Social Network for 21 st century teachers on test creation by studying the problems and demands in examination creating including the demand on online training for Bangkok schools' teachers and executives using questionnaires. After that the information data gained from step 1 was used to design and develop the training curriculum then quality checked by the expert. The result found that the developed online training curriculum was in the highest suitability level. Step 2 was the effectiveness evaluation of the online training curriculum based on Micro Learning and Online Social Network for 21st century teachers on test creation by using the developed training curriculum with 30 Bangkok teachers from simple random sampling from the respondents in step 1 and willing to participate in online training on test creation.

The result found that 1) the evaluation on the teachers' test creation ability compared to the ability before and after joining the training from development scores of each trained teacher -2 teachers $(6.67 \%)$ performed very high development, 21 teachers $(70.00 \%)$ performed high development and 7 teachers $(23.33 \%)$ performed moderate development and 2) the quality evaluation in accordance with the assessment standards of The Joint Committee on Standards for Educational Evaluation which was evaluated by 30 participating teachers and executives of the 30 teachers were in good level for 4 standards. The standard with the highest mean was propriety standards $\left(\overline{\mathrm{x}}^{-}=4.78\right)$. The next one was feasibility standards $(\overline{\mathbf{x}}=4.74)$, Utility standards $(\overline{\mathbf{x}}=4.71)$ and accuracy standards $(\overline{\mathbf{x}}=4.64)$, respectively.
\end{abstract}

Keywords

Training curriculum, Online training curriculum, Micro learning

Article Received: 10 August 2020, Revised: 25 October 2020, Accepted: 18 November 2020

\section{Introduction}

Presently, the world is in rapid advancement from the use of technology to connect every information together. The social changing trend in the 21 st century then broadly affects the way of life in the society. Thai society in the past was simple with rarely change with was open and accepted the outside culture to adapt in the environment and way of life. When entering the 21 st century, Thailand also changes to the World's trend due to the advancement of science, technology and information. The mentioned matters are the important factors for the age of borderless communication. The education development then is essential in order to prepare for the future (NawapohnChalaruk, 2015).

Teacher plays the important role in education process as their main task is to perform teaching as well as develop the quality student. Teacher needs to be professional, expert on both academic and modern teaching techniques in accordance with the World's changes in technology and society for the learners to develop Thai society to compete with the global society (SomwangPhithiyanuwat. 2000). The desirable features of teachers in the 21 st century are the insight knowledge of the subject, teaching expertise, able to develop the courses, lessons and course book planning focusing on the learners, invent the lessons that every learner can learn, allow the learners to learn from knowledge seeking, help the learners to understand the nature of science, math and technology and give the learners the opportunity to develop the motto, skills helping the learners to have sustainable learning. (Upper Secondary Education Bureau, 2014). Therefore, the teacher needs to continuously develop their skills because the quality of the teacher directly affects the students'. The high-quality teacher can greatly provide knowledge to the students.

The ability to create examination is the part of measurement and evaluation performance which is the important performance of the teacher as the examination is the essential tool to evaluate the ability of the students. The information from the examination reflects the quality of education, helps the teacher see the guideline to develop and improve the students including the teaching. SumreongBoonruengrat (2004) explained that the education evaluation tool helps the teachers, counselors, executives and researchers, acts as the tool to inspect the development of the students' intelligence, mind and society how much it develops according to the educational target. The result is used to improve or develop the students and education process. This is in accordance with UtumpohnJamonman (2002) who explained that examination provides the result of students' performance, teachers' teaching, educationist planning and the management of the educational institute. Therefore, the examination is influential on education, students, teachers, executives, people, educational institutes, educational development plans and the country eventually. The teacher then must not ignore the importance of test creation as ChawanPearatkul (2009) explained that the 
teacher has important task to create the better and unique measurement tool for the perfect measurement. The tool can be created in any way to stimulate the students to express the behaviors that the teacher needs to evaluate with the method to measure such behavior. Which examination is better depends on how accurate and suitable the examination points out the effectiveness line. Therefore, the researcher team are interested in developing the online training curriculum for 21 st century teachers on test creation by using the lesson focusing on micro learning together with online social network. Micro learning is the gradual learning using small amount of time that can be used with daily routine of working people such as watching 2-3 minute video clip, doing built-in answer quiz or reading short passages. This way can facilitate the participants in term of data accessing, travelling as well as reduce budget in each training in the long term.

\section{Aim}

To develop the online training curriculum based on Micro Learning and Online Social Network for 21st century teachers on test creation.

To evaluate the effectiveness of $\mathrm{O}$ online training curriculum based on Micro Learning and Online Social Network for 21 st century teachers on test creation.

\section{Definitions}

Training Curriculummeans a total package of learning activities designed to achieve. the objectives of the training program.

Online Training is the distance learning, or e-learning and online training is a form of instruction that takes place completely on the internet. It involves a variety of multimedia elements, including graphics, audio, video, and web-links, which all can be accessed through one's internet browser.

Micro learning meanssmall learning units and short-term learning activities. The term is used in e-learning and related fields in the sense of learning processes in mediated environments.

\section{Methods}

This research aimed to develop the online training curriculum based on Micro Learning and Online Social Network for 21 st century teachers on test creation.

The methodology was divided into 2 steps.

Step 1 was the development of online training curriculum based on Micro Learning and Online Social Network for 21 st century teachers on test creation.

1. Study the problems and demands in examination creating including the demand on online training for Bangkok schools' teachers and executives using questionnaires.

2. Design and develop training curriculum using the information from step 1 in the training development.

3. Draft online training curriculum composing of principles, course objectives, structure, training time, content, training activities and measurement and evaluation of training.

4. Review the suitability of the course by the expert.

5. Improve and develop the course.

Step 2 was the effectiveness evaluation of online training curriculum based on Micro Learning and Online Social Network for 21st century teachers on test creation by using the developed course with 30 Bangkok teachers in the sampling group answering the questionnaire from simple random sampling. The online training was done from December 2019 - February 2020 then the online training curriculum effectiveness evaluation was divided into 2 parts - 1) the evaluation on the teachers' test creation ability compared to the ability before and after joining the training from development scores of each trained teacher and 2) the quality evaluation in accordance with the assessment standards of The Joint Committee on Standards for Educational Evaluation by 30 participating teachers and 30 executives.

\section{Results}

This research was the development of the online training curriculum based on Micro Learning and Online Social Network for 21 st century teachers on test creation with the result as followed:

1) The development of the online training curriculum based on Micro Learning and Online Social Network for 21 st century teachers on test creation.

1.1 The study of problem and demand of teacher on creating examination and participating in online training by using face validity test from the expert and gather the data from the teachers and executives in Bangkok from the simple randomization in 50 districts of Bangkok, 1 school per district. After that 10 of teachers and executives from each school were randomized for total 500. It was found that 462 participants $(92.4 \%)$ were interested in test creation training and 357 participants $(71.4 \%)$ were interested in joining online training. However, 116 participants were uncertain if they could participate in scheduled online training. Therefore, 241 participants $(42.8 \%)$ were interested on participating in online training on test creation and were certain about their participation.

1.2 The researcher team have drafted the online curriculum by presenting the information from step 1 with the curriculum development then created online training curriculum composing of main objective, structure, duration, content, training activity and measurement and training evaluation.

1.3 The inspection of online training curriculum suitability by the expert found that the concordance index was between .80 to 1.00 and in the highest suitability level.

2) The evaluation of the effectiveness of online training curriculum based on Micro Learning and Online Social Network for 21 st century teachers on test creation.

1.1 The evaluation on the teachers' test creation abilitcompared to the ability before and after joining the training from development scores of each trained teacher -2 teachers $(6.67 \%)$ performed very high development, 21 teachers $(70.00 \%)$ performed high development and 7 teachers $(23.33 \%)$ performed moderate development as shown in table 1 . 
Table1 Number and percentage of teachers participating online training with developmental scores after receiving training, classified by development level.

\begin{tabular}{cccc}
\hline \hline $\begin{array}{c}\text { Relative Gain } \\
\text { Score }\end{array}$ & $\begin{array}{c}\text { Development } \\
\text { level } \\
76-100\end{array}$ & $\begin{array}{c}\text { No. of } \\
\text { teachers }\end{array}$ & Percentage \\
\hline $51-75$ & High & 2 & 6.67 \\
\hline $26-50$ & Moderate & 7 & 70.00 \\
\hline $0-25$ & Low & - & - \\
\hline & & 30 & 100 \\
\hline \hline
\end{tabular}

1.2 The quality evaluation in accordance with the assessment standards of The Joint Committee on Standards for Educational Evaluation which was evaluated by 30 participating teachers and executives of the 30 teachers were in good level for 4 standards. The standard with the highest mean was propriety standards $(\overline{\mathrm{x}}=4.78)$. The next one was feasibility standards $(\overline{\mathrm{x}}=4.74)$, Utility standards ("x" $=$ $4.71)$ and accuracy standards $(\overline{\mathrm{x}}=4.64)$, respectively. As shown in table 2.

Table 2Mean and standard deviation of online training on test creation quality evaluation

\begin{tabular}{l|c|c|c|c|c|c|c|c|c}
\hline \hline \multirow{2}{*}{ Items } & \multicolumn{3}{c|}{ Teachers } & \multicolumn{3}{c|}{ Executives } & \multicolumn{3}{c}{ Total } \\
\cline { 2 - 11 } & $\overline{\mathrm{x}}$ & S.D. & Interpret & $\overline{\mathrm{x}}$ & S.D. & Interpret & $\overline{\mathrm{x}}$ & S.D. & Interpret \\
\hline 1. Utility standards & 4.71 & 0.23 & Good & 4.19 & 0.24 & Good & 4.45 & 0.21 & Good \\
\hline 2. Feasibility standards & 4.74 & 0.17 & Good & 4.23 & 0.26 & Good & 4.48 & 0.24 & Good \\
\hline 3. Propriety standards & 4.78 & 0.15 & Very good & 4.36 & 0.20 & Good & 4.57 & 0.23 & Very good \\
\hline 4. Accuracy standards & 4.64 & 0.22 & Very good & 3.99 & 0.28 & Good & 4.31 & 0.27 & Good \\
\hline \hline
\end{tabular}

\section{Discussion}

The research results revealed that the evaluation on the teachers' test creation ability compared to the ability before and after joining the training from development scores of each trained teacher -2 teachers $(6.67 \%)$ performed very high development, 21 teachers $(70.00 \%)$ performed high development and 7 teachers $(23.33 \%)$ performed moderate development consistent withthe research of Soraya (2010) showed that development of an online learning, there were significant differences between learners' pretest and posttest at .05 level. For the quality evaluation in accordance with the assessment standards of The Joint Committee on Standards for Educational Evaluation which was evaluated by 30 participating teachers and executives of the 30 teachers were in good level for 4 standards. The standard with the highest mean was propriety standards $(\overline{\mathrm{x}}-\mathbf{=} .78)$. The next one was feasibility standards $(\overline{\mathrm{x}}-=4.74)$, Utility standards $(\overline{\mathrm{x}}-=4.71)$ and accuracy standards $(\overline{\mathrm{x}}-=$ 4.64)consistent with the research of Phusit (2012)presented that the strategy for promoting self-regulated learning strategies in online context composed of video, studying paper, voice, assignment, web-board, online chatting and social network have affects the level of their self-regulated learning strategies and the learning achievement at statistical significance.

\section{Suggestions}

Recommendation for applications

1. The interest parties should study online training curriculum to be able to arrange the complete training according to the content.
2. Since it is online training curriculum, the constant communication with the participation is needed to create the inspiration in the course.

3. As the ability to create examination is the skill from practicing, those who are interested need to stimulate the participants to practice creating and commenting the examination for the mutual learning.

Recommendations for the next research

1. The training period and result follow up after the training should be added to develop the further training curriculum.

2. There should be other online curriculums to help reduce the training budget, increase data accessibility for the participants, reduce travel burden and able to manage training duration by themselves.

\section{Acknowledgment}

The author is very grateful to Srinakharinwirot University (www.swu.ac.th) for encouragement and supporting.

\section{References}

[1] ChawanPearatkul (2009). Assessment technique. 7th edition. Bangkok. Vitoon Binding \& Printing.

[2] NawapohnChalaruk (2015). "Role of teacher and 21st century education". Far Eastern University academic journal Year 9 Vol 1 (May-July) : 64-71

[3] Mac Education. (2014). Teacher of 1st century. Bangkok : Plan Printing Co., Ltd.

[4] PassakornRuangrong et al. (2014). "Education technology and Thai teacher in 21 st century". Panyapiwat Journal. Year 5. Special edition (May) : 195-207 http://www.rand.org/pubs/research_briefs/ 2005/RAND_RB9050.pdf

[5] Upper Secondary Education Bureau, Office of the Basic Education Commission. (2014). Guideline for education in 21st century. Bangkok : The Agricultural Cooperative Federation of Thailand. Limited.

[6] SirichaiGarnchanawasri. (2009). Traditional examination theory. 6th edition. Bangkok : Chulalongkorn University Printing House.

[7] SomwangPiiyanuwat. (2014). Training documentation "Developing test construction and examination guidelines". Bangkok : VajirawutWitthayalai School. 
[8] SumroengBoonruangrit et al. (2004). Educational Measurement and Evaluation: 3rd Specific Encyclopedia of Education. Educational Measurement and Evaluation Program. Encyclopedia of Education. Bangkok : Copy and Print.

[9] UtumpohnChamonman. (2002). Examination: Creation and Development. Bangkok. Funny Publishing.

[10] Soraya Sarasuphab. (2010). Development of an online social network learning model utilizing situate learning theory to enhance intercultural awareness of foreign language learners. Doctoral Thesis, Department of Educational Research and Psychology, Graduate School, Chulalongkorn University.

[11] PhusitWonglorsaichon. (2012). Research and development of a strategy manual for promoting self-regulated learning strategies in online context of university students with a data collection design through online system. Doctoral Thesis, Department of Educational Research and Psychology, Graduate School, Chulalongkorn University.

[12] Retni S. B. and Harlis, D. N. (2020). High Order Thinking Skills for Biology Education: Applied Microbiology Learning Videos Based on Jambi Local Wisdom. Universal Journal of Educational Research 8(2): 689-694, DOI: 10.13189/ujer.2020.082504DOI:10.13189/ ujer.2020.080242 